CLINICAL STUDY

\title{
C-peptide and the risk for incident complications and mortality in type 2 diabetic patients: a retrospective cohort study after a 14-year follow-up
}

\author{
S Bo, L Gentile ${ }^{1}$, A Castiglione ${ }^{2}$, V Prandi, S Canil, E Ghigo and G Ciccone ${ }^{2}$ \\ Department of Internal Medicine, University of Turin, Corso Dogliotti 14, 10126 Turin, Italy, ${ }^{1}$ Diabetic Clinic, Hospital of Asti, Asti, Italy and \\ ${ }^{2}$ Unit of Cancer Epidemiology, University of Turin, Turin, Italy \\ (Correspondence should be addressed to S Bo; Email: sbo@molinette.piemonte.it)
}

\begin{abstract}
Objective: C-peptide, a cleavage product of insulin, exerts biological effects in patients with type 1 diabetes mellitus, but its role in type 2 diabetes mellitus is controversial. Our aim was to examine the associations between fasting C-peptide levels and all-cause mortality, specific-cause mortality and the incidence of chronic complications in patients with type 2 diabetes.

Design: Retrospective cohort study with a median follow-up of 14 years.

Methods: A representative cohort of 2113 patients with type 2 diabetes mellitus and a subgroup of 931 individuals from this cohort without chronic complications at baseline from a diabetic clinic were studied.

Results: Patients with higher C-peptide levels had higher baseline BMI and triglyceride and lower HDL-cholesterol values. During the follow-up, $46.1 \%$ of the patients died. In a Cox proportional hazard model, after multiple adjustments, no significant association was found between the C-peptide tertiles and all-cause mortality or mortality due to cancer, diabetes or cardiovascular diseases. In the subgroup of 931 patients without chronic complications at baseline, the incidence of microvascular complications decreased from the first to the third C-peptide level tertile, while the incidence of cardiovascular disease did not differ. The risks for incident retinopathy (hazard ratio $(\mathrm{HR})=0.33$; 95\% confidence interval (CI) 0.23-0.47), nephropathy (HR $=0.27$; 95\% CI 0.18-0.38) and neuropathy ( $\mathrm{HR}=0.39 ; 95 \%$ CI $0.25-0.61$ ) were negatively associated with the highest C-peptide tertile, after adjusting for multiple confounders.

Conclusions: Higher baseline C-peptide levels were associated with a reduced risk of incident microvascular complications but imparted no survival benefit to patients with type 2 diabetes mellitus.
\end{abstract}

European Journal of Endocrinology 167 173-180

\section{Introduction}

C-peptide has long been considered to be a biologically inert portion of proinsulin. More recently, C-peptide has been found to bind to endothelial cells, renal tubular cells and fibroblasts in a stereospecific manner and to stimulate $\mathrm{Na}^{+}-\mathrm{K}^{+}$-ATPase, endothelial nitric oxide synthase activities and nuclear factor- $\kappa \mathrm{B}$ activation in endothelial cells exposed to hyperglycaemia $(1,2)$. Human C-peptide exerts beneficial effects on vascular and neural dysfunction in diabetic rats (3); in type 1 diabetic patients with low or absent plasma C-peptide levels, it augments blood flow in skin and skeletal muscle, improves nerve function and decreases urinary albumin excretion and glomerular hyperfiltration $(1,4$, $5,6,7,8)$. Its renoprotective effect has recently been confirmed by the nearly complete reversal of the morphological changes in renal proximal tubular cells that were experimentally induced by tumour growth factor $\beta 1$ (9). Residual $\beta$-cell secretion, evaluated by the measurement of fasting $C$-peptide levels, has been prospectively associated with a reduced incidence of microvascular complications in type 1 diabetes (10). In contrast, these protective effects have not been found in non-diabetic humans or animals, suggesting that no further activity could be obtained by an additional increment in the C-peptide concentration at physiological levels (1). Furthermore, the role of C-peptide is not well defined in type 2 diabetes, a disease that is now considered to be a consequence of the reduced $\beta$-cell function superimposed on a condition of insulin resistance (11). Some prospective studies have found that residual insulin secretion has a protective effect on microvascular complications (12), while others have failed to find such an association $(13,14)$. However, previous studies have included either patients who were already complicated at baseline $(12,13)$ or a small number of individuals $(12,14)$. Finally, no data 
regarding the association between residual insulin secretion and major outcomes, such as all-cause mortality and mortality due to cardiovascular diseases, are available in type 2 diabetic patients, while a few cross-sectional studies show contrasting data about the association of $\mathrm{C}$-peptide and macrovascular complications $(15,16)$.

The aims of this study were to evaluate after a 14-year follow-up period: i) the association between baseline fasting serum C-peptide levels with all-cause and specific-cause mortality in a cohort of 2113 patients with type 2 diabetes mellitus; and ii) the association between baseline C-peptide levels and the incidence of micro- and macrovascular complications in a subgroup of 931 individuals from the previous cohort of type 2 diabetic patients without chronic complications at baseline.

\section{Subjects and methods}

All 2113 patients with type 2 diabetes attending the diabetes clinic in Asti, a province in northern Italy, were evaluated in 1996-1997, as previously reported $(17,18)$. They represented $1.6 \%$ of the reference population (134 646 subjects). Therefore, because the prevalence of known type 2 diabetes was $2 \%$ in northern Italy (19), our cohort included $\sim 80 \%$ of the patients with known diabetes in the study area. Of these patients, 931 (44.1\%) were free of any chronic complications (retinopathy, nephropathy, neuropathy and cardiovascular diseases) at baseline. The baseline data were obtained from the clinical records.

At the diabetes clinic, all the patients were examined every 4 months, the HbA1c levels and blood pressure were measured at each visit, and the patients had annual plasma lipid measurements and screenings for chronic complications. Centralised laboratory measurements were used. Height and weight were measured by a trained nurse, with the patient wearing light clothing but not shoes. The arterial blood pressure was measured by the same nurse in the morning after an overnight fast using a mercury sphygmomanometer with an appropriate cuff size, after a $5 \mathrm{~min}$ rest in the sitting position, with the arm being supported at heart level. The values reported were the averages of the last three measurements reported in the clinical records.

The laboratory methods have been previously described $(17,18)$. The fasting serum C-peptide levels were measured once at the time of the enrolment of the patients, using an enzyme immunoassay (DAKO C-peptide, Cambridgeshire, UK); the coefficients of variation were $3.3-5.7 \%$. HbAlc was measured using HPLC (Bracco, Milan, Italy; reference range 2.4-4.7\%); the values reported were the means of the last three determinations.

Retinopathy was diagnosed via an ophthalmoscopic examination and/or retinal photography. A fundoscopy was performed through dilated pupils by an ophthalmologist who was experienced with diabetic retinopathy. In the group with retinopathy (any degree), a retinal photograph was taken, in accordance with the European protocol for diabetic retinopathy (20). Nephropathy was established by an albumin excretion rate of more than $20 \mu \mathrm{g} / \mathrm{min}$ in at least two out of three urine collections within 6 months (immunoturbidimetric method), gross proteinuria or elevated serum creatinine levels. Distal symmetric polyneuropathy was diagnosed by the presence of neuropathic symptoms, an abnormal vibration perception threshold, the absence of $\geq 2$ ankle or knee reflexes and/or an abnormal electromyographic test. Autonomic neuropathy was diagnosed by a loss of heart rate variability or postural hypotension. A cardiovascular disease diagnosis was based on documented events that were recorded by a physician (angina, myocardial infarction, a coronary artery bypass graft or other invasive procedures to treat coronary artery disease, transient ischaemic attacks, strokes, gangrene, amputation, vascular surgery, intermittent claudication, absent foot pulses and abnormal brachial and posterior tibial blood pressures, as determined by Doppler techniques).

Information on the vital status of each patient and the causes of death of those who had died were collected from June to December 2010 from the demographic files in the town of residence or death.

The underlying cause of death was derived from death certificates and coded according to the International Classification of Diseases, Ninth Revision (ICD9). Of the causes of death, cardiovascular diseases (ICD $410-414,430-438,440)$, cancer (140-239) and diabetes (250) were considered.

Data relative to any incident chronic complications at follow-up were obtained from the clinical records of the diabetes clinic. All the procedures were in accordance with the Helsinki Declaration as revised in 2000. Informed consent was obtained from all the patients at baseline and the Local Ethics Committee approved the study protocol.

\section{Statistical analyses}

The patients were analysed according to the baseline C-peptide tertiles. The characteristics of the patients were described using either means and s.D.s or medians and interquartile ranges for the continuous variables. Percentage frequencies were used for the categorical variables.

Baseline differences among C-peptide tertiles were tested by $\chi^{2}$ test, ANOVA F-test and Kruskal-Wallis test, according to the type of variable. The overall survival was defined as the time from the enrolment until the date of death or the end of observation.

A Cox proportional hazard model was used to estimate the adjusted hazard ratios (HRs) and 95\% confidence intervals (95\% CIs) for all-cause mortality of 
each C-peptide tertile, after adjusting for prognostic factors (age, sex, BMI, smoking, the time since diagnosis, insulin treatment and the $\mathrm{HbA1c}$, systolic blood pressure, HDL-cholesterol, triglyceride values and any complications at baseline).

In order to evaluate the association between C-peptide tertiles and specific causes of death, a Fine and Gray model, taking into account deaths for all causes as competing events, was used to estimate the specific-cause mortality HRs and 95\% CIs, adjusted for prognostic factors.

The same statistical model for competing events was used to estimate the HRs and 95\% CIs for the incidence of each chronic complication at follow-up by adjusting for age, sex, BMI, smoking, the time since diagnosis, insulin treatment, the $\mathrm{HbA1c}$, systolic blood pressure, HDL-cholesterol and triglyceride values.

Statistical analyses were performed using Stata 9.2 (StataCorp LP, College Station, TX, USA) and R (version 2.12.1).

\section{Results}

The individuals in the lowest C-peptide tertile had longer baseline time since diagnosis, higher $\mathrm{HbAlc}$ levels and increased prevalence of retinopathy and nephropathy. These patients were also more frequently on insulin treatment. Patients in the third tertile exhibited higher baseline BMI and triglyceride values and lower HDL-cholesterol values (Table 1).

The vital status and cause of death were ascertained for $99.9 \%$ of the cohort (2112/2113). During a 14-year follow-up, 973/2112 patients died (46.1\%).
The survival curve for each C-peptide tertile is shown in Fig. 1. Patients who died during the follow-up were significantly older and more frequently on insulin treatment. These patients had longer durations of diabetes, higher HbA1c levels and systolic blood pressure, more chronic complications and lower BMI and cholesterol values (data not shown). No significant association was found between the C-peptide tertiles and either the all-cause mortality or the mortality due to cancer, diabetes or cardiovascular diseases in a Cox proportional hazard model after adjusting for multiple confounders and considering the deaths from other causes as competing events (Table 2).

Patients with higher C-peptide levels exhibited an increased risk for death due to 'other causes' (mainly infections), which occurred in 22/325 (6.8\%), 26/312 $(8.3 \%)$ and $37 / 336(11.0 \%)$ of the first, second and third tertiles respectively.

The incidence of chronic complications was evaluated in the subgroup of 931 patients from the entire cohort, who were free from any chronic complications at baseline. Of these patients, $60.4 \%$ developed at least one complication during the follow-up. The cumulative incidences of any chronic complications and specific complications in each $\mathrm{C}$-peptide tertile are reported in Fig. 2. The incidences of retinopathy, nephropathy and neuropathy decreased from the first to the third C-peptide tertiles (Table 3).

Higher levels of C-peptide were negatively associated with all the incident complications, with the exception of cardiovascular disease, after adjusting for multiple confounders (Table 4).

The data did not change significantly after excluding the patients who were treated with insulin only

Table 1 Baseline characteristics of all type 2 diabetic patients by C-peptide tertiles. Values are mean (s.D.) or percentages; time since diagnosis and triglyceride values are reported as medians (interquartile ranges).

\begin{tabular}{|c|c|c|c|c|}
\hline Baseline & 1 tertile $\leq 0.47 \mathrm{nmol} / \mathrm{l}$ & 2 tertile $0.47-0.80 \mathrm{nmol} / \mathrm{l}$ & 3 tertile $\geq 0.80 \mathrm{nmol} / \mathrm{l}$ & $P$ value \\
\hline Number & 715 & 643 & 755 & \\
\hline Age (years) & $65.6(11.3)$ & $66.9(10.2)$ & $65.6(10.9)$ & $0.048^{\mathrm{a}}$ \\
\hline Males $(\%)$ & 44.1 & 44.9 & 45.2 & $0.904^{b}$ \\
\hline Time since diagnosis (years) & $11.0(12.0)$ & $9.0(12.0)$ & $7.0(11.0)$ & $<0.001^{\mathrm{c}}$ \\
\hline Smoking (\%) & 14.6 & 15.6 & 15.1 & $0.873^{\mathrm{b}}$ \\
\hline Insulin therapy (\%) & 38.2 & 24.1 & 20.1 & $<0.001^{\mathrm{b}}$ \\
\hline BMl $\left(\mathrm{kg} / \mathrm{m}^{2}\right)$ & $27.7(5.1)$ & $28.5(5.0)$ & $30.0(5.2)$ & $<0.001^{a}$ \\
\hline $\mathrm{HbA1c}(\%)$ & $6.9(1.3)$ & $6.4(1.3)$ & $6.5(1.3)$ & $<0.001^{\mathrm{a}}$ \\
\hline Systolic blood pressure $(\mathrm{mmHg})$ & $143.0(11.5)$ & $143.7(10.8)$ & $144.3(11.5)$ & $0.087^{\mathrm{a}}$ \\
\hline Diastolic blood pressure $(\mathrm{mmHg})$ & $82.8(4.4)$ & $83.2(4.2)$ & $83.5(4.5)$ & $0.012^{\mathrm{a}}$ \\
\hline Total cholesterol $(\mathrm{mmol} / \mathrm{l})$ & $5.4(1.1)$ & $5.3(1.1)$ & $5.4(1.1)$ & $0.572^{\mathrm{a}}$ \\
\hline HDL-cholesterol ( $\mathrm{mmol} / \mathrm{l})$ & $1.3(0.3)$ & $1.2(0.3)$ & $1.1(0.3)$ & $<0.001^{\mathrm{a}}$ \\
\hline Triglycerides $(\mathrm{mmol} / \mathrm{l})$ & $1.2(0.8)$ & $1.4(0.8)$ & $1.6(0.9)$ & $<0.001^{\mathrm{C}}$ \\
\hline Retinopathy (\%) & 28.5 & 17.0 & 17.9 & $<0.001^{\mathrm{b}}$ \\
\hline Nephropathy (\%) & 25.0 & 20.7 & 20.4 & $0.061^{\mathrm{b}}$ \\
\hline Neuropathy (\%) & 9.5 & 9.5 & 8.5 & $0.737^{\mathrm{b}}$ \\
\hline Cardiovascular disease (\%) ${ }^{d}$ & 29.1 & 33.4 & 29.5 & $0.165^{\mathrm{b}}$ \\
\hline Any chronic complications (\%) & 58.6 & 55.2 & 53.9 & $0.178^{\mathrm{b}}$ \\
\hline
\end{tabular}




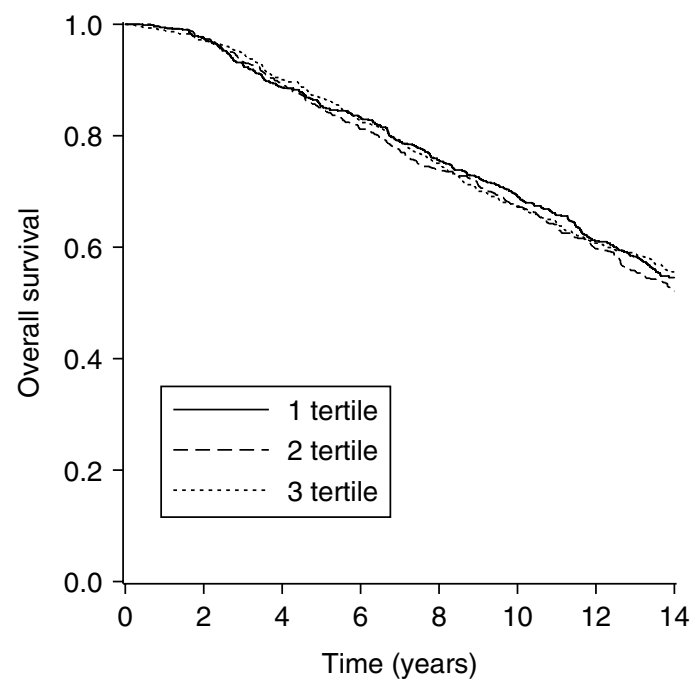

Figure 1 Survival curves by C-peptide tertiles in 2112 type 2 diabetic patients after 14-year follow-up.

( $n=356 / 2112 ; 16.8 \%$ ), the patients with C-peptide values $\leq 0.33 \mathrm{nmol} / \mathrm{l} \quad(\leq 1 \mathrm{ng} / \mathrm{ml} ; n=450 / 2112$; $21.3 \%)$ or the patients with impaired renal function $(n=165 / 2112 ; 7.8 \%)$.

\section{Discussion}

Our results indicated that initially complication-free type 2 diabetic patients with higher baseline fasting C-peptide levels had a significantly reduced incidence of neuropathy, nephropathy and retinopathy after a 14-year follow-up. However, neither the all-cause mortality nor the mortality for cancer, diabetes or cardiovascular diseases was reduced in patients with higher C-peptide levels.

It is well known that even low levels of residual pancreatic secretion prevent incident microvascular complications in type 1 diabetes (10); experimental studies have suggested that the administration of C-peptide directly reduces glomerular lesions by exerting anti-apoptotic and anti-fibrotic effects and by increasing blood flow to the muscle, skin, kidneys and peripheral nerves, and that it exerts a corrective effect on neurotrophic factors and cytoskeletal proteins by increasing endothelial nitric oxide (NO) synthase levels, thereby stimulating $\mathrm{Na}^{+}-\mathrm{K}^{+}$-ATPase, activating kinases and acting on transcription factor NF- $\mathrm{BB}(2,4$, $6,7,8,9,21,22)$. Thus, type 1 diabetes has been recently proposed as a dual-hormone deficit disease (23).

In type 2 diabetes, the data are contrasting. Epidemiological studies have found cross-sectional associations between low C-peptide levels and either microvascular or macrovascular complications and cardiovascular risk factors in type 2 diabetes $(15,16,17)$, and most experiments with C-peptide supplementation have promoted vascular lesions and insulin resistance $(24,25)$. In type 2 diabetes, elevations in C-peptide levels are usually observed as a consequence of insulin resistance. The effects of C-peptide supplementation cannot be demonstrated in patients with normal or high C-peptide levels; it is likely that, under these conditions, receptor saturation and downregulation occur such that no additional biological activity can be obtained from an additional increase in C-peptide levels $(1,21,22,23)$. Furthermore, there are differences between type 1 and type 2 diabetes in terms of progression and in the types of lesions of microvascular complications (23).

Patients who developed incident chronic complications were more frequently on insulin treatment

Table 2 Adjusted hazard ratios for mortality for all-cause and for specific causes in all type 2 diabetic patients by C-peptide tertiles.

\begin{tabular}{|c|c|c|c|}
\hline & 1 tertile & 2 tertile & 3 tertile \\
\hline \multicolumn{4}{|l|}{ All causes } \\
\hline Number of deaths (\%) & $325(45.5)$ & $312(48.5)$ & $336(44.6)$ \\
\hline $\mathrm{HR}^{\mathrm{a}}(95 \% \mathrm{Cl})$ & 1 & $1.24(0.92-1.65)$ & $1.10(0.93-1.30)$ \\
\hline \multicolumn{4}{|l|}{ Cardiovascular diseases } \\
\hline Number of deaths (\%) & $164(22.9)$ & $141(21.9)$ & $153(20.3)$ \\
\hline $\mathrm{HR}^{\mathrm{a}}(95 \% \mathrm{Cl})$ & 1 & $0.93(0.74-1.18)$ & $0.92(0.73-1.17)$ \\
\hline \multicolumn{4}{|l|}{ Cancer } \\
\hline Number of deaths (\%) & $82(11.5)$ & $86(13.4)$ & $88(11.7)$ \\
\hline $\mathrm{HR}^{\mathrm{a}}(95 \% \mathrm{Cl})$ & 1 & $1.09(0.80-1.49)$ & $0.99(0.71-1.40)$ \\
\hline \multicolumn{4}{|l|}{ Diabetes } \\
\hline Number of deaths (\%) & $33(4.6)$ & $33(5.1)$ & $32(4.2)$ \\
\hline $\mathrm{HR}^{\mathrm{a}}(95 \% \mathrm{Cl})$ & 1 & $1.20(0.73-1.95)$ & $1.14(0.68-1.92)$ \\
\hline \multicolumn{4}{|l|}{ Other causes } \\
\hline Number of deaths (\%) & $46(6.4)$ & $52(8.1)$ & $63(8.4)$ \\
\hline $\mathrm{HR}^{\mathrm{a}}(95 \% \mathrm{Cl})$ & 1 & $1.43(0.95-2.15)$ & $1.62(1.08-2.44)$ \\
\hline
\end{tabular}

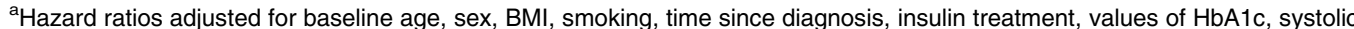
blood pressure, HDL-cholesterol and triglycerides, presence of retinopathy, nephropathy, neuropathy and cardiovascular diseases. 

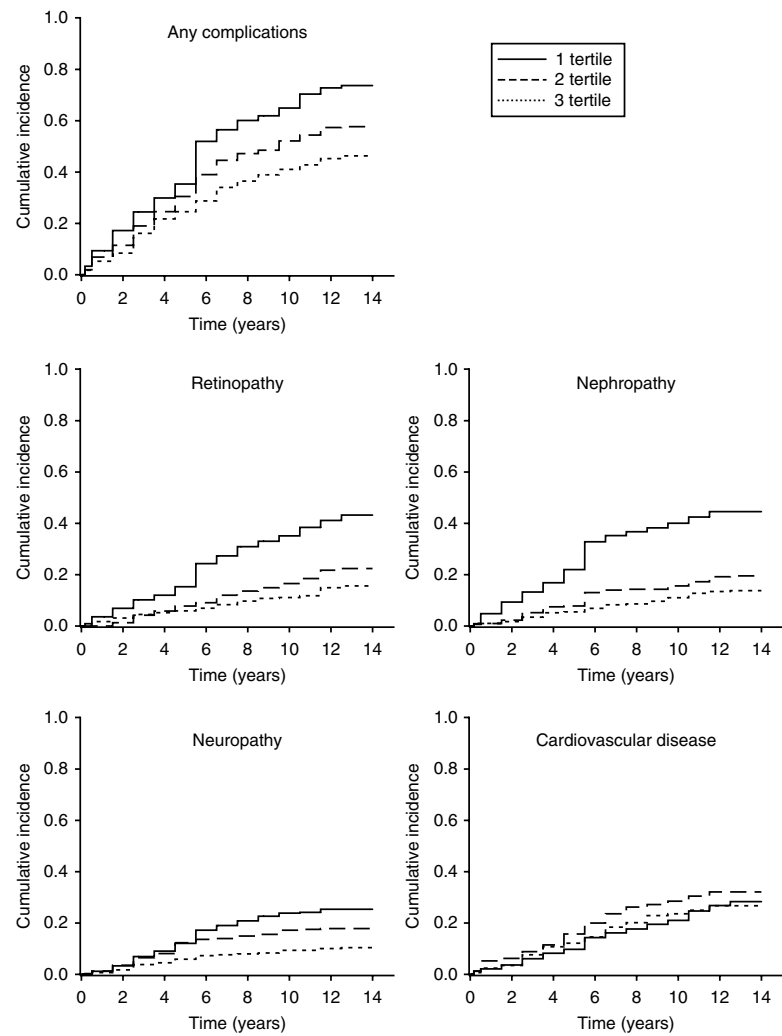

Figure 2 Cumulative incidence of any and specific chronic complications by C-peptide tertiles in 931 type 2 diabetic patients without any complications at baseline.

and had lower C-peptide levels, a longer time since diagnosis and a worse glycaemic control. These features indicate progressive $\beta$-cell failure. We found a strong inverse association between C-peptide levels and the duration of diabetes, confirming the progressive deterioration of $\beta$-cell function in type 2 diabetes over time (26). The inverse association between C-peptide values and the risk for microvascular complications suggests that, in type 2 diabetic patients with $\beta$-cell failure, low fasting $\mathrm{C}$-peptide values are indicative of the risk for developing microvascular complications. It can be argued that low $\mathrm{C}$-peptide is merely a marker of $\beta$-cell function and low levels indicate $\beta$-cell failure. The association between low C-peptide and increased risk of microvascular complications would suggest a lack of ability to self-regulate glycaemia, which in turn pre-disposes to microvascular disease.

In contrast, patients with higher C-peptide levels showed a combination of risk factors, such as hypertension, low HDL-cholesterol, hypertriglyceridemia and obesity, which might be the consequence of insulin resistance and, possibly, C-peptide resistance. Therefore, despite their significantly lower durations of diabetes, the incidence of cardiovascular complications did not differ among the $\mathrm{C}$-peptide groups.

The literature regarding the association between C-peptide levels and arteriosclerosis is highly controversial. Some studies have demonstrated the beneficial effects of C-peptide on vessels by inhibiting smooth muscle cell proliferation and migration and antiinflammatory activity in endothelial cells $(2,27,28)$. Other studies have revealed C-peptide deposition in the arteriosclerotic lesions of diabetic patients, chemotactic activity towards monocytes and CD4+ lymphocytes and the induction of vascular smooth muscle cell proliferation $(24,25)$.

It has been postulated that C-peptide normally acts as a counter-regulatory peptide towards the effects of insulin on vessels; the insulin/C-peptide relationship is perturbed when exogenous insulin is administered alone (28). In type 2 diabetes, the situation is more complex because of the coexistence of multiple cardiovascular risk factors, associated with increased C-peptide levels, the potential down-regulation of C-peptide receptors and the less clear interaction between insulin and C-peptide.

Table 3 Baseline characteristics in 931 patients without complications at baseline by C-peptide tertiles. Values are mean (s.D.) or percentages; time since diagnosis and triglyceride values are reported as medians (interquartile ranges).

\begin{tabular}{|c|c|c|c|c|}
\hline & 1 tertile $\leq 0.50 \mathrm{nmol} / \mathrm{l}$ & 2 tertile $0.50-0.80 \mathrm{nmol} / \mathrm{l}$ & 3 tertile $>0.80 \mathrm{nmol} / \mathrm{l}$ & $P$ value \\
\hline Number & 333 & 308 & 290 & \\
\hline Age (years) & $62.8(12.0)$ & $64.3(9.5)$ & $64.0(11.5)$ & $0.187^{\mathrm{a}}$ \\
\hline Males $(\%)$ & 38.4 & 42.5 & 40.5 & $0.573^{b}$ \\
\hline Time since diagnosis (years) & $8.0(10.0)$ & $7.0(10.0)$ & $5.0(10.0)$ & $<0.001^{\mathrm{C}}$ \\
\hline Smoking (\%) & 14.1 & 14.3 & 16.9 & $0.578^{\mathrm{b}}$ \\
\hline Insulin therapy (\%) & 22.2 & 12.3 & 14.5 & $<0.002^{\mathrm{b}}$ \\
\hline BMI $\left(\mathrm{kg} / \mathrm{m}^{2}\right)$ & $27.7(5.1)$ & $29.1(5.0)$ & $30.1(5.2)$ & $<0.001^{a}$ \\
\hline $\mathrm{HbA} 1 \mathrm{c}(\%)$ & $6.7(1.4)$ & $6.2(1.2)$ & $6.3(1.3)$ & $<0.001^{a}$ \\
\hline Systolic blood pressure (mmHg) & $141.4(11.9)$ & $142.7(11.0)$ & $142.7(11.2)$ & $0.262^{\mathrm{a}}$ \\
\hline Diastolic blood pressure $(\mathrm{mmHg})$ & $82.7(4.5)$ & $83.1(4.4)$ & $83.6(4.5)$ & $0.056^{\mathrm{a}}$ \\
\hline Total cholesterol $(\mathrm{mmol} / \mathrm{l})$ & $5.3(1.1)$ & $5.4(1.0)$ & $5.3(1.0)$ & $0.224^{a}$ \\
\hline HDL-cholesterol $(\mathrm{mmol} / \mathrm{l})$ & $1.3(0.3)$ & $1.2(0.3)$ & $1.1(0.3)$ & $<0.001^{a}$ \\
\hline Triglycerides $(\mathrm{mmol} / \mathrm{l})$ & $1.2(0.8)$ & $1.4(0.8)$ & $1.5(0.9)$ & $<0.001^{\mathrm{c}}$ \\
\hline
\end{tabular}

${ }^{a}$ ANOVA F-test.

${ }^{\mathrm{b}} \chi^{2}$ test.

'Kruskal-Wallis test. 
Table 4 Association of baseline C-peptide tertiles with chronic complications at follow-up in 931 patients without complications at baseline.

\begin{tabular}{|c|c|c|c|}
\hline & 1 tertile & 2 tertile & 3 tertile \\
\hline \multicolumn{4}{|l|}{ Retinopathy } \\
\hline Number of events (\%) & $144(43.2)$ & $69(22.4)$ & $47(16.2)$ \\
\hline $\mathrm{HR}^{\mathrm{a}}(95 \% \mathrm{Cl})$ & 1 & $0.51(0.38-0.68)$ & $0.33(0.23-0.47)$ \\
\hline \multicolumn{4}{|l|}{ Nephropathy } \\
\hline Number of events (\%) & $149(44.7)$ & $61(19.8)$ & $40(13.8)$ \\
\hline $\mathrm{HR}^{\mathrm{a}}(95 \% \mathrm{Cl})$ & 1 & $0.40(0.29-0.54)$ & $0.27(0.18-0.38)$ \\
\hline \multicolumn{4}{|l|}{ Neuropathy } \\
\hline Number of events (\%) & $86(25.8)$ & 55 (17.9) & $32(11.0)$ \\
\hline $\mathrm{HR}^{\mathrm{a}}(95 \% \mathrm{Cl})$ & 1 & $0.72(0.50-1.04)$ & $0.39(0.25-0.61)$ \\
\hline \multicolumn{4}{|l|}{ Cardiovascular disease } \\
\hline Number of events (\%) & $98(29.4)$ & 101 (32.8) & 79 (27.2) \\
\hline $\mathrm{HR}^{\mathrm{a}}(95 \% \mathrm{Cl})$ & 1 & $1.18(0.89-1.57)$ & $0.93(0.68-1.27)$ \\
\hline \multicolumn{4}{|l|}{ Any chronic complications } \\
\hline Number of events (\%) & $246(73.9)$ & $179(58.1)$ & $137(47.2)$ \\
\hline $\mathrm{HR}^{\mathrm{a}}(95 \% \mathrm{Cl})$ & 1 & $0.72(0.60-0.88)$ & $0.52(0.42-0.65)$ \\
\hline
\end{tabular}

${ }^{\mathrm{a}} \mathrm{Hazard}$ ratios adjusted for baseline age, sex, BMI, smoking, time since diagnosis, insulin treatment, values of $\mathrm{HbA} 1 \mathrm{c}, \mathrm{systolic}$ blood pressure, HDL-cholesterol and triglycerides.

The inconsistencies among previous studies that have evaluated the associations between C-peptide levels and chronic complications in type 2 diabetes may be due to differences in the study designs and populations $(12,13,14,15,16,17,21,22,24,25,29)$; however, these differences again highlight the complexity of these relationships in a disease with a pathophysiology that is still incompletely defined.

Preserving $\beta$-cell function is one of the aims of treating type 2 diabetes in the attempt to delay the natural course of the disease (26). Certain strategies, such as starting insulin therapy as early as possible, avoiding drugs that over-stimulate $\beta$-cells (such as sulphonylureas) and using new drugs that selectively enhance insulin secretion, have been advocated to rescue $\beta$-cell function. However, when we considered hard end points (such as mortality), instead of single complications, no benefits from increased C-peptide levels were evident. Our results remained consistent after adjusting for the time since diagnosis, glycaemic control, insulin treatment and other confounders. Intriguingly, in non-diabetic patients with breast cancer, fasting C-peptide levels are positively associated with an increased risk for all-cause and breast cancer-associated death (30). These associations might be due to the increased BMIs of women with higher C-peptide levels, because of the well-documented association between obesity and excess mortality (31). Indeed, these associations persist after adjusting for the BMI values. Similarly, in our patients, avoiding the irreversible loss of $\beta$-cell mass and function did not confer any survival benefits to type 2 diabetic patients. Indeed, patients in the highest C-peptide tertile exhibited increased mortality due to 'other causes', particularly infection. This relationship is difficult to explain. Patients in the third C-peptide tertile showed increased BMIs and the features of the metabolic syndrome, as shown in our cross-sectional study (17). Impaired immune function, including decreased cytokine production, reduced responses to antigen/mitogen stimulation, decreased macrophage and dendritic cell function, and natural killer cell impairment have been demonstrated in obese individuals (32). Impaired immune responses lead to an increased susceptibility to infections (32). Furthermore, increased inflammation, altered adipokine signalling and the metabolic changes associated with insulin resistance could affect immune responses $(32,33)$.

Even if the findings of this retrospective analysis need prospective replication in cohorts of new-onset type 2 diabetes, a suggestion can be derived from these data, owing to the discordant relationships between $\beta$-cell functions and outcomes. Strategies for the management of type 2 diabetes should probably derive from trials designed around major end points (all-cause and specific-cause mortality) instead of surrogate end points (HbAlc values or the incidence of chronic complications).

\section{Limitations and strengths of the study}

The patients were not enrolled at the onset of the disease. This fact may represent a possible source of selection bias. However, population-based diabetic cohorts that are enrolled at the onset of the disease are quite difficult to assemble and follow.

We cannot exclude the possibility that some of the patients in the lower C-peptide tertile may be type 1 diabetic misclassified as type 2 diabetic. Nevertheless, it is unlikely that, in our representative cohort of diabetic patients, all the patients who had C-peptide values $\leq 0.33 \mathrm{nmol} / \mathrm{l}(21.3 \%)$ were type 1 diabetic. Furthermore, the prevalence of patients on insulin treatment was comparable to that of other Italian diabetic cohorts $(19,34)$. The major site of C-peptide catabolism is the kidney; therefore, C-peptide levels may have been 
elevated in patients with renal impairment; nevertheless, after excluding individuals with impaired renal function, the data did not change significantly. Only one fasting blood sample for C-peptide was collected, leading to the possibility of random errors; furthermore, the possible variation over time of the variable was not taken into account. However, this could have rather weakened the associations or masked weak associations. Furthermore, C-peptide assessment is highly reproducible and considered to be an appropriate measure of residual $\beta$-cell function because it is secreted in equimolar amounts with respect to insulin and is not removed in the first pass through the liver. We adjusted the analyses for many potential confounders, but residual confounding cannot be excluded.

The strengths of this study include the fact that the studied cohort was representative of the diabetic patients from the study area and all laboratory measurements were centralised. In addition, the length and completeness of the follow-up were high and the sample size was sufficient to estimate HRs with narrow 95\% CIs.

\section{Conclusions}

Higher fasting concentrations of $\mathrm{C}$-peptide are associated with a reduced risk for several chronic complications but not all-cause or specific-cause mortality in type 2 diabetic patients.

\section{Declaration of interest}

The authors declare that there is no conflict of interest that could be perceived as prejudicing the impartiality of the research reported.

\section{Funding}

This study was supported by a grant from Regione Piemonte, 2009.

\section{Author contribution statement}

S Bo participated in the conception and design of the study, supervision of data collection, data analysis, interpretation of the findings of the study, manuscript writing and revision. L Gentile participated in the data collection, interpretation of the findings of the study and manuscript revision. A Castiglione participated in the data analysis, interpretation of the findings of the study and manuscript revision. V Prandi and S Canil participated in the data collection, interpretation of the findings and manuscript revision. E Ghigo participated in the design of the study and interpretation of the findings of the study, manuscript writing and revision. G Ciccone participated in the conception and design of the study, interpretation of the findings of the study, manuscript writing and revision.

\section{References}

1 Wahren J, Ekberg K, Johansson J, Henriksson M, Pramanik A, Johansson BL, Rigler R \& Jörnvall H. Role of C-peptide in human physiology. American Journal of Physiology. Endocrinology and Metabolism 2000278 E759-E768.
2 Luppi P, Cifarelli V, Tse H, Piganelli J \& Trucco M. Human C-peptide antagonises high glucose-induced endothelial dysfunction through the nuclear factor-kappaB pathway. Diabetologia 2008 51 1534-1543. (doi:10.1007/s00125-008-1032-x)

3 Ido Y, Vindigni A, Chang K, Stramm L, Chance R, Heath W, Di Marchi R, Cera ED \& Williamson J. Prevention of vascular and neural dysfunction in diabetic rats by C-peptide. Science 1997 277 563-566. (doi:10.1126/science.277.5325.563)

4 Forst T, Kunt T, Pohlmann T, Goitom K, Engelbach M, Beyer J \& Pfützner A. Biological activity of C-peptide on the skin microcirculation in patients with insulin dependent diabetes mellitus. Journal of Clinical Investigation $1998 \quad 101$ 2036-2041. (doi:10.1172/JCI2147)

5 Jensen ME \& Messina EJ. C-peptide induces a concentrationdependent dilation of skeletal muscle arterioles only in presence of insulin. American Journal of Physiology. Heart and Circulatory Physiology 1999276 H1223-H1228.

6 Johansson B-L, Borg K, Fernqvist-Forbes E, Kernell A, Odergren T \& Wahren J. Beneficial effects of C-peptide on incipient nephropathy and neuropathy in patients with type I diabetes - a threemonth study. Diabetic Medicine 200017 181-189. (doi:10.1046/j. 1464-5491.2000.00274.x)

7 Johansson B-L, Kernell A, Sjöberg S \& Wahren J. Influence of combined C-peptide and insulin administration on renal function and metabolic control in diabetes type 1. Journal of Clinical Endocrinology and Metabolism 199377 976-981. (doi:10.1210/jc. 77.4.976)

8 Ekberg K, Brismar T, Johansson B-L, Jonsson B, Lindström P \& Wahren J. Amelioration of sensory nerve dysfunction by C-peptide in patients with type 1 diabetes. Diabetes $2003 \mathbf{5 2} 536-541$. (doi:10.2337/diabetes.52.2.536)

9 Hills CE, Al-Rasheed N, Al-Rasheed N, Willars GB \& Brunskill NJ. C-peptide reverses TGF- $\beta 1$-induced changes in renal proximal tubular cells: implications for treatment of diabetic nephropathy. American Journal of Physiology. Renal Physiology 2009296 F614-F621. (doi:10.1152/ajprenal.90500.2008)

10 Steffes MW, Sibley S, Jackson M \& Thomas W. $\beta$-Cell function and the development of diabetes-related complications in the Diabetes Control and Complications Trial. Diabetes Care 200326 832-836. (doi:10.2337/diacare.26.3.832)

11 Pratley RE \& Weyer C. The role of impaired early insulin secretion in the pathogenesis of type II diabetes mellitus. Diabetologia 2001 44 929-945. (doi:10.1007/s001250100580)

12 Suzuki K, Watanabe K, Motegi T \& Kajinuma H. High prevalence of proliferative retinopathy in diabetic patients with low pancreatic $\beta$-cell capacity. Diabetes Research and Clinical Practice 19896 45-52. (doi:10.1016/0168-8227(89)90056-9)

13 Klein R, Klein BE \& Moss SE. The Wisconsin Epidemiologic Study of diabetic retinopathy, XVI. The relationship of C-peptide to the incidence and progression of diabetic retinopathy. Diabetes 1995 44 796-801. (doi:10.2337/diabetes.44.7.796)

14 Gottsater A, Ahmed M, Fernlund P \& Sundkvist G. Autonomic neuropathy in type-2 diabetic patients is associated with hyperinsulinemia and hypertriglyceridemia. Diabetic Medicine 199916 49-54. (doi:10.1046/j.1464-5491.1999.00001.x)

15 Kim BY, Jung CH, Mok JO, Kang SK \& Kim CH. Association between serum C-peptide levels and chronic microvascular complications in Korean type 2 diabetic patients. Acta Diabetologia 201249 9-15. (doi:10.1007/s00592-010-0249-6)

16 Sari R \& Balci MK. Relationship between C-peptide and chronic complications in type-2 diabetes mellitus. Journal of the National Medical Association 200597 1113-1118.

17 Bo S, Cavallo-Perin P, Gentile L, Repetti E \& Pagano G. Relationship of residual beta-cell function, metabolic control and chronic complications in type 2 diabetes mellitus. Acta Diabetologia 2000 37 125-129. (doi:10.1007/s005920070014)

18 Bo S, Cavallo-Perin P \& Gentile L. Prevalence of patients reaching the targets of good control in normal clinical practice. A cohortbased study in type 2 diabetes. Diabetes Care 1999222092. (doi:10.2337/diacare.22.12.2092b) 
19 Bruno G, Bargero G, Vuolo A, Pisu E \& Pagano G. A populationbased prevalence survey of known diabetes mellitus in northern Italy based upon multiple independent sources of ascertainment. Diabetologia 199235 851-856. (doi:10.1007/BF00399931)

20 Retinopathy Working Party. A protocol for screening for diabetic retinopathy in Europe. Diabetic Medicine 19918 263-267. (doi:10.1111/j.1464-5491.1991.tb01583.x)

21 Hills CE, Brunskill NJ \& Squires PE. C-peptide as a therapeutic tool in diabetic nephropathy. American Journal of Nephrology 201031 389-397. (doi:10.1159/000289864)

22 Kamiya H, Zhang W \& Sima AF. The beneficial effects of C-peptide on diabetic polyneuropathy. Review of Diabetic Studies 20096 187-202. (doi:10.1900/RDS.2009.6.187)

23 Hills CE \& Brunskill NJ. Cellular and physiological effects of C-peptide. Clinical Science 2009116 565-574. (doi:10.1042/ CS20080441)

24 Walcher D, Babiak C, Poletek P, Rosenkranz S, Bach H, Betz S, Durst R, Grüb M, Hombach V, Strong J \& Marx N. C-peptide induces vascular smooth muscle cell proliferation. Circulation Research 200699 1181-1187. (doi:10.1161/01.RES.0000251 231.16993.88)

25 Marx N \& Walcher D. C-peptide and atherogenesis: C-peptide as a mediator of lesion development in patients with type 2 diabetes mellitus? Experimental Diabetes Research 20082008385108. (doi:10.1155/2008/385108)

26 Weng J, Li Y, Xu W, Shi L, Zhang Q, Zhu D, Hu Y, Zhou Z, Yan X, Tian H, Ran X, Luo Z, Xian J, Yan L, Li F, Zeng L, Chen Y, Yang L, Yan S, Liu J, Li M, Fu Z \& Cheng H. Effect of intensive insulin therapy on $\beta$-cell function and glycaemic control in patients with newly diagnosed type 2 diabetes: a multicentre randomised parallel-group trial. Lancet 2008371 1753-1760. (doi:10.1016/S0140-6736(08)60762-X)

27 Kobayashi Y, Naruse K, Hamada Y, Nakashima E, Kato K, Akiyama N, Kamiya H, Wataraj A, Nakae M, Oiso Y \& Nakamura J. Human proinsulin C-peptide prevents proliferation of rat aortic smooth muscle cells cultured in high-glucose conditions. Diabetologia 2005 48 2396-2401. (doi:10.1007/s00125-005-1942-9)
28 Mughal RS, Scragg JL, Lister P, Warburton P, Riches K, O'Regan DJ, Ball SG, Turner NA \& Porter KE. Cellular mechanisms by which proinsulin C-peptide prevents insulin-induced neointima formation in human saphenous vein. Diabetologia 201053 1761-1771. (doi:10.1007/s00125-010-1736-6)

29 Töyry JP, Niskanen LK, Mäntysaari MJ, Länsimies EA, Haffner SM, Miettinen HJJ \& Uusitupa MIJ. Do high proinsulin and C-peptide levels play a role in autonomic nervous dysfunction? Circulation $1997961185-1191$.

30 Irwin ML, Duggan C, Wang CY, Smith AW, McTiernan A, Baumgartner RN, Baumgartner KB, Bernstein L \& BallardBarbash R. Fasting C-peptide levels and death resulting from all causes and breast cancer: the Health, Eating, Activity, and Lifestyle Study. Journal of Clinical Oncology 201129 47-53. (doi:10.1200/JCO.2010.28.4752)

31 McGee DL. Body mass index and mortality: a meta-analysis based on person-level data from twenty-six observational studies. Annals of Epidemiology 200515 87-97. (doi:10.1016/j.annepidem. 2004.05.012)

32 Karlsson EA \& Beck MA. The burden of obesity on infectious disease. Experimental Biology and Medicine 2010235 1412-1424. (doi:10.1258/ebm.2010.010227)

33 Elks CM \& Francis J. Central adiposity, systemic inflammation, and the metabolic syndrome. Current Hypertension Reports 201012 99-104. (doi:10.1007/s11906-010-0096-4)

34 Bo S, Ciccone G, Rosato R, Villois P, Appendino G, Ghigo E \& Grassi G. Cancer mortality reduction and metformin. A retrospective cohort study in type 2 diabetic patients. Diabetes, Obesity \& Metabolism 201214 23-29. (doi:10.1111/j.1463-1326.2011. 01480.x)

Received 30 January 2012

Revised version received 6 April 2012

Accepted 10 May 2012 